Article

\title{
Experimental Investigations on Steam Generation in Nanofluids under Concentrated Solar Radiation
}

\author{
Xin Jin, Guiping Lin and Haichuan Jin * (D) \\ Laboratory of Fundamental Science on Ergonomics and Environmental Control, School of Aeronautic Science and \\ Engineering, Beihang University, Beijing 100191, China; jinx@buaa.edu.cn (X.J.); gplin@buaa.edu.cn (G.L.) \\ * Correspondence: jinhaichuan@buaa.edu.cn
}

check for updates

Citation: Jin, X.; Lin, G.; Jin, H. Experimental Investigations on Steam Generation in Nanofluids under Concentrated Solar Radiation. Energies 2021, 14, 3985. https:// doi.org/10.3390/en14133985

Academic Editors: Karunesh Kant and Atul Sharma

Received: 3 June 2021

Accepted: 29 June 2021

Published: 2 July 2021

Publisher's Note: MDPI stays neutral with regard to jurisdictional claims in published maps and institutional affiliations.

Copyright: (c) 2021 by the authors. Licensee MDPI, Basel, Switzerland. This article is an open access article distributed under the terms and conditions of the Creative Commons Attribution (CC BY) license (https:// creativecommons.org/licenses/by/ $4.0 /)$.

\begin{abstract}
Developing renewable energy, especially solar energy related, is of great importance for securing our future energy society. Steam generation in nanofluids based on solar radiation has been increasingly studied. It has been determined that the efficiency of steam generation is significantly enhanced when nanoparticles are seeded into the fluid owing to their unique radiative heat transfer performance. The nanoparticles trap solar energy inside the fluid and convert it into thermal form, which dramatically accelerates the steam generation process. In this study, we experimentally investigated different nanofluids that directly absorb solar energy to generate steam. Ag nanofluid, Au nanofluid and MWCNT nanofluid with different concentration have been carefully investigated. We analyzed the temperature increase and steam generation combined with the calculation of the efficiency factor from radiative heat transfer. The heating power and steam generation power of different nanofluids and the same nanofluid with different concentrations were compared. For $\mathrm{Au}$ nanofluid with concentration of $0.5 \mathrm{wt} \%$, the absorbed solar energy for heating the volume and generating steam is 6 and 40 times higher than those of pure water, respectively. We concluded that localized boiling generates steam rapidly in nanofluids based on the observation of three types of nanofluids. Furthermore, the heating power and steam generation power of different nanofluids increase with concentration. Moreover, the difference between the efficiency factors results in varied volume heating and steam generation efficiencies for different nanofluids despite identical concentrations.
\end{abstract}

Keywords: solar energy; nanofluids; steam generation; efficiency factor

\section{Introduction}

The increase in the consumption of fossil fuels has led to the development of clean and renewable energy sources, among which solar energy is crucial [1]. Steam production is widely used in various fields, such as refrigeration devices, energy storage, and large-scale power generation [2-5]. However, steam is generally obtained by burning fossil fuels or through electric heating, which is not environmentally friendly. Therefore, the application of clean and renewable solar energy to produce steam is increasingly researched [6-9]. At present, several challenges exist in the utilization of solar energy, and efficient solar photothermal conversion is extremely difficult in the case of solar thermal energy applications. The energy conversion efficiency of the most of the solar thermal utilizations is dramatically limited by the ill heat transfer process: solar energy to the surface, then the surface to the working fluid, when heat loss to the ambient during the heat transfer process takes major part of the heat transfer. The volume absorption of solar energy will significantly increase the absorption efficiency. Therefore, the concept of nanoparticle-based direct absorption was developed to enhance the solar energy harvesting performance. This concept requires nanoparticles seeding into the working fluid to achieve enhanced energy conversion efficiency. Eventually, the absorbed solar energy has been trapped inside the working fluid to reduce the heat loss to the ambient. 
For traditional solar thermal collectors (STC), the solar energy is absorbed firstly by the engineered solid surface, which is normally coated by high absorption materials. Then, the absorbed solar energy will be transferred through thermal conduction from the working fluid. Conversely, the direct absorption solar collector (DASC) does not absorb solar energy through the surface, the properly selected nanoparticles will absorb the solar energy volumetrically, which means the solar energy will be trapped inside the working fluid. This volumetric absorption process addresses the limitation of surface heat transfer process, which is normally associated with conventional STCs, considerably increasing the photothermal conversion efficiency by selecting the absorption spectrum [10-13]. Metal nanoparticles, such as $\mathrm{Ag}$ and $\mathrm{Au}$ have been extensively investigated owing to their surface plasmon resonance effect [14-17]. Many researchers have investigated the photothermal conversion efficiency of nanoparticle-based work fluid. Such as Otanicar et al. [18], they compared different nanofluids, including carbon based and metal based nanoparticles. The conclusion can be reached that many characters can affect the solar harvesting efficiency, especially the nanoparticle size, material and the volume concentration. Furthermore, the photothermal conversion efficiency was increased by $5 \%$ when compared with the based working fluid (i.e., water). The plasmonic nanoparticles (PNP) proposed by Zhang et al. [19] has been experimentally investigated. An improved citrate reduction method was employed to produce gold nanoparticles (GNPs), which was tested under a solar simulator to show the solar energy harvesting efficiency. They concluded that compared with other materials, the GNP nanofluid had the best energy efficiency. Furthermore, the specific absorption rate (SAR) was firstly proposed by them to evaluate the performance of solar energy harvesting, when $S A R=10 \mathrm{~kW} / \mathrm{g}$ was obtained at the lowest particle concentration examined $(0.15 \mathrm{ppm})$. Additionally, the efficiency could be increased by $20 \%$ when gold nanoparticles were inside the working fluid. Some simulative works have been done by researchers since the last decade. For example, Luo et al. [20] developed a numerical model to simulate the photothermal conversion efficiency for nanoparticles based DASCs, where the radiative heat transfer equations together with the conductive and convective heat transfer inside the nanofluids were under consideration. Compared to the based fluid, the temperature of the nanofluids was increased by $30-100 \mathrm{~K}$ for nanofluids and the photothermal conversion efficiency was enhanced by $2-25 \%$. What's interesting, the overall heat transfer efficiency for nanofluid based DASC was almost twice of that of the surface based solar receiver. They concluded that with very low concentration of nanoparticles, the volume temperature and the energy efficiency can be significantly enhanced. In our previous research $[11,21]$, the photothermal conversion efficiency can be significantly enhanced when nanoparticles are seeded inside the working fluid (i.e., the efficiency of Au nanofluid with concentration of $5.8 \mathrm{ppm}$ is 4 times higher than that of pure water).

Using nanoparticles to achieve steam generation is considered highly effective owing to its steam production rate and remarkable efficiency of capturing solar energy [14,22-26]. Recently, nanoparticles have been used to directly generate steam by consuming solar energy in addition to heating base fluids [18,22,24,27-29]. Most of the working fluids, such as water and ethanol, have a weak ability to absorb solar energy [30]. However, adding a small volume fraction of nanoparticles to the fluid can effectively improve its photothermal conversion efficiency [31-33]. Based on this phenomenon, researchers have proposed the concept of direct absorption $[19,33]$ of solar energy using nanofluids.

Thus far, an efficiency of $80 \%$ has been reported in the direct steam production [22] when the solar radiation is concentrated by 1000 times, wherein the working fluid temperature is approximately $6{ }^{\circ} \mathrm{C}$ despite using only $20 \%$ of the solar energy to heating the volume fluid. One hypothesis states that the nanobubbles can be generated around the nanoparticles with high temperature. After then the nanobubbles will rise to the surface of the nanofluid and release steam [34]. Several numerical studies [22,30] support the possible generation of nanobubble around the nanosized particles, when the non-equilibrium heat transfer model is employed. Several other studies reported that nanofluids can generate 
steam rapidly under concentrated sunlight [35-37]. The results of experimental studies and numerical calculations [35,38-40] have proved the rationality of the nanobubble hypothesis. These investigations were performed under high concentration conditions, such as 1000 times concentrated solar intensity. Furthermore, studies have experimentally and theoretically confirmed [35,38-42] that nanobubbles can possibly be formatted around the nanoparticles when the temperature is high [43], especially under intensive laser heating $\left(>1000 \mathrm{MW} / \mathrm{m}^{2}\right)$. Moreover, simulations have [44] indicated that the interfacial thermal resistance between the volume and the particles increases with the surface temperature, which may further increase the surface temperature of the nanoparticles. If the laser power and pulse are controlled at a good state, the nanobubble generation rate and steam production quantity can be dramatically increased. Moreover, for medical applications, the cells closing to the nanoparticles can be significantly damaged by the pressure waves from the nanobubbles, which has attracted intensive attention from researchers [45].

However, researchers have verified that the generation of nanobubbles is nearly impossible when the concentrated solar intensity is low [46]. Under such conditions, the probable reason for bubble formation is local boiling in the overheated area caused by the uneven distribution of temperature and solar radiation, as discussed previously [10,12]. For the experiments [47] with low solar intensity, which is less than $50 \mathrm{~kW} / \mathrm{m}^{2}$, it is difficult for the nanofluids to attain the boiling point. Consequently, the steam generation should be closely related to the surface evaporation, when the localized boiling is impossible inside the volume. Most of the previous investigations focus on the vaporized mass change and evaporation efficiency. However, the difference in the efficiency of steam generation between different nanofluids combined with the characteristics of bubble formation is not investigated. Additionally, determining whether the mechanism of steam generation in nanofluids under solar radiation is identical for nanofluids with different nanoparticles warrants further investigations.

In our previous research $[10,12]$, the steam generation can be dramatically enhanced when Au nanoparticles participate, which is mainly due to the localized boiling and surface evaporation. However, whether or not the material of nanoparticles affects the steam generation process is still unknown. Therefore, in this study, we experimentally investigated different nanofluids as working fluids that directly absorb solar energy for steam generation. The temperature distribution of the working fluid and the generated steam were analyzed using an infrared thermal imaging camera, and the bubble generation processes were compared based on videos captured by a high-speed camera. Different concentrations of $\mathrm{Ag}$, Au, and multiwalled carbon nanotube (MWCNT) nanofluids were prepared, and the effect of various concentrations and types of nanofluids on steam generation was studied. Additionally, we discuss the photothermal conversion characteristics for different nanofluids with varying concentrations. Furthermore, the energy harvesting efficiency of volume heating of the fluids and steam generation has been investigated.

\section{Materials and Methods}

\subsection{Preparation of Nanofluids}

We used both one-step and two-step methods to synthesize different types of nanofluids. The Au nanofluid was formulated through the one-step method. The detailed information can be seen in our previous research [10,11]. Table 1 depicts the transmission electron microscopy (TEM) image of GNPs indicating the morphology information. Most of the small-sized and large-sized Au nanoparticles are spherical and oval, respectively, with an average size of approximately $20-30 \mathrm{~nm}$. 
Table 1. Overview of the nanofluids.

\begin{tabular}{|c|c|c|c|c|}
\hline $\begin{array}{c}\text { Type of } \\
\text { Nanoparticles }\end{array}$ & $\begin{array}{c}\text { Concentrations } \\
(w t \% o)\end{array}$ & $\begin{array}{l}\text { Particle Size } \\
\text { (nm) }\end{array}$ & $\begin{array}{c}\text { Preparation } \\
\text { Method }\end{array}$ & $\begin{array}{c}\text { Micro-Nano } \\
\text { Structure }\end{array}$ \\
\hline $\mathrm{Au}$ & $\begin{array}{c}0.02 \\
0.1 \\
0.5\end{array}$ & $20 \sim 30$ & One-step & \\
\hline $\mathrm{Ag}$ & $\begin{array}{c}0.01 \\
0.02 \\
0.1 \\
0.2\end{array}$ & $20 \sim 30$ & Two-step & \\
\hline MWCNT & $\begin{array}{l}0.2 \\
0.4 \\
0.8 \\
1.6\end{array}$ & $50 \times 500$ & Two-step & \\
\hline
\end{tabular}

The two-step method [31] was used to produce stable Ag and MWCNT (Multiwalled Carbon Nanotube) nanofluids. The nanoparticle powder was purchased from Beijing DK Nano Technology Co., LTD, Beijing, China. Initially, the powder was dispersed in the DI water and placed in an ultrasonic bath (Thermo Fisher Scientific, FB11207, Waltham, MA, USA) for $30 \mathrm{~min}$. This dispersed solution was processed by an ultrasonic cell disruption (UCD) system (Thermo Fisher Scientific, FB705) with 50\% power for $2 \mathrm{~h}$. Table 1 depicts the TEM image and the MWCNT nanofluid characterized by scanning electron microscopy (SEM), respectively.

Before the experiment, the nanofluids were processed by the UCD System with $50 \%$ power for $2 \mathrm{~h}$. After 2 months of standing, the nanofluids were tested using an ultraviolet (UV)-spectrophotometer (Shimadzu UV-1800, Shimadzu Corporation, Kyoto, Japan) to compare the changes in absorption. We observed that the difference of absorbance was less than $1 \%$, indicating excellent stability. The overview of the nanofluids can be seen in Table 1. The photographs of different nanofluids can be seen in Figure 1.

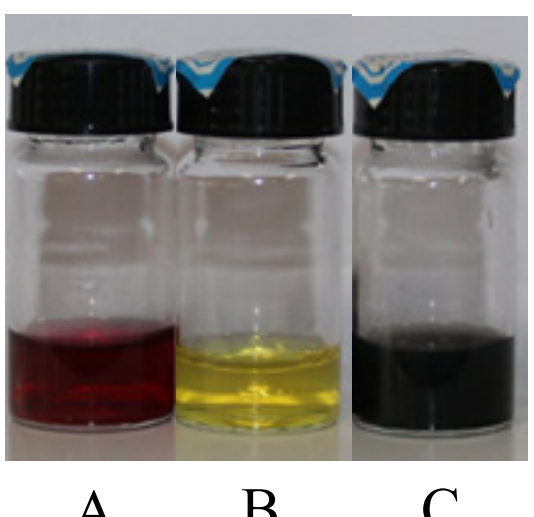

Figure 1. The photographs of (A) Au nanofluid and (B) Ag nanofluid (C) MWCNT nanofluid before the experiment. 


\subsection{Experimental Setup}

Figure 2 illustrates the experimental setup. The experiments were conducted using natural sunlight, wherein a Fresnel lens of dimensions $0.5 \mathrm{~m} \times 0.5 \mathrm{~m}$ was employed to concentrate the sunlight by 500 times. The solar radiation was maintained at approximately $500 \mathrm{~kW} / \mathrm{m}^{2}$ in all experiments, and we assumed that uniform radiation was generated from the focused sunlight. A high-precision infrared camera (Fluke TiX640 with $30 \mathrm{~mm}$ lens) was used to capture the temperature distribution of different samples. Additionally, we used a high-speed camera (Canon 70D with 18-135 mm lens) to record the bubble generation. Seven K-type thermocouples with a precision of $\pm 0.1^{\circ} \mathrm{C}$ (Omega 5TC-TT-K-30-36, Norwalk, CT, USA) were connected to a data acquisition system (National Instruments PIXe-1073). $\mathrm{T} 1$ to $\mathrm{T} 5$ thermocouples were placed inside the sample fluid to measure the temperature within the fluid, whereas the remaining thermocouples, $\mathrm{T} 6$ and $\mathrm{T} 7$, were placed above the fluid-air interface to measure the temperature variation of the steam above the sample fluid. Furthermore, a solar intensity sensor with a measurement uncertainty of $2.0 \%$ was placed near the Fresnel lens to measure the variation of solar intensity with time. The images, temperature data, and solar intensity data were stored in a personal computer connected to the high-speed camera, infrared camera, data acquisition system, and solar intensity sensor. Figure 2B depicts the schematic of the experimental system.

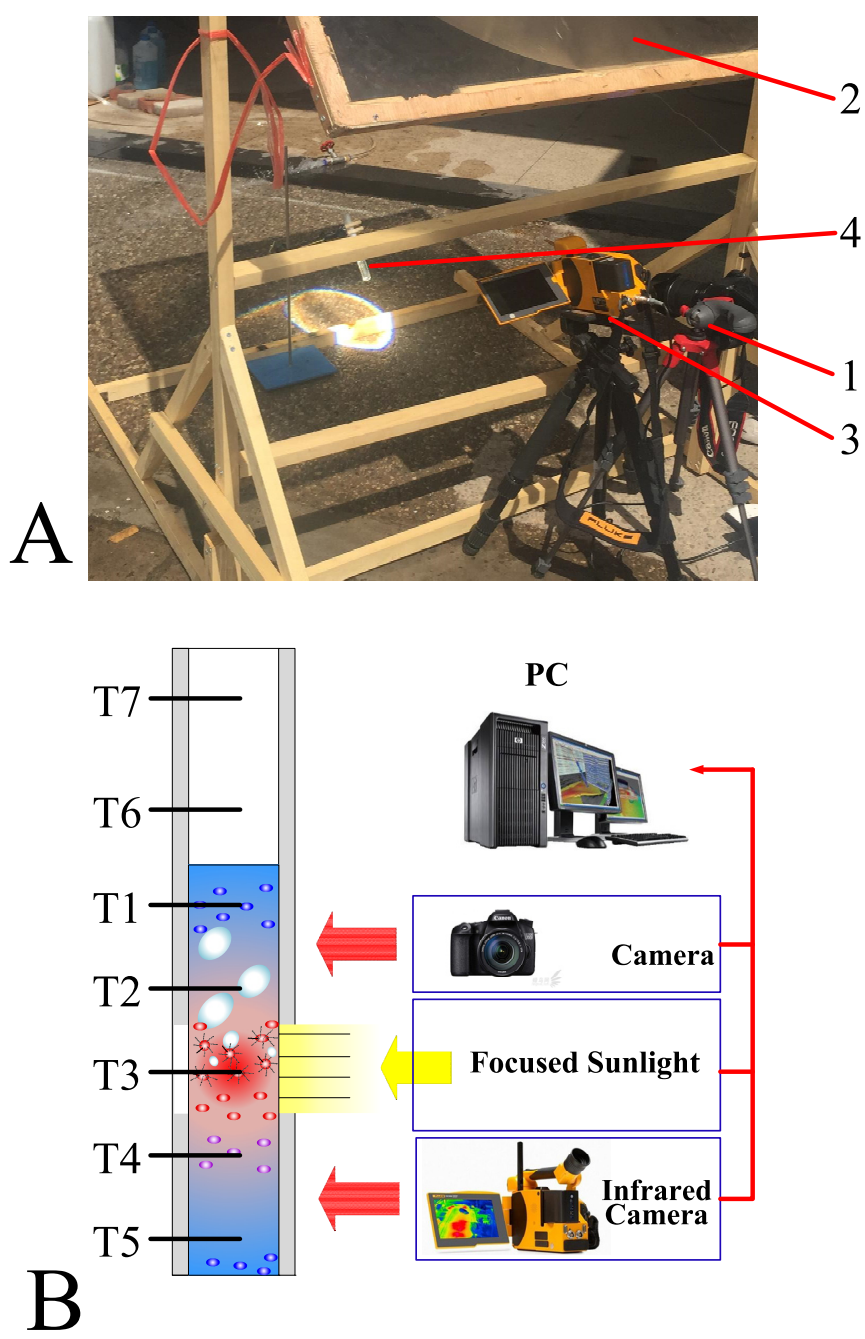

Figure 2. (A) Image of the experimental setup: 1. Camera capturing the bubble formation; 2 . fresnel lens of dimensions $0.5 \mathrm{~m} \times 0.5 \mathrm{~m}$; 3. infrared camera; 4 . test tube with samples. (B) Schematic of the experimental system with seven K-type thermocouples placed inside the test tube. 


\section{Results and Discussion}

\subsection{Temperature Profile of Nanofluids under Concentrated Sunlight}

Previously, we observed that the sunlight absorption enhances significantly when nanoparticles are inside the working fluid $[10,11,21]$, which is water in this study. When concentrated sunlight illuminates the nanofluid, the temperature at different positions immediately increases, as illustrated in Figure 3. Initially, the temperature increases rapidly owing to a large amount of input solar energy. However, the increment in temperature declines after attaining the boiling point, which can be attributed to the increased heat loss at a high ambient temperature. At approximately $80 \mathrm{~s}$, the temperature of areas near T3 and T4, which are close to the focal point of sunlight, is approximately $100{ }^{\circ} \mathrm{C}$ owing to the focused sunlight. Conversely, certain other areas require more time to boil as T1 and T5 attain the boiling point at approximately $200 \mathrm{~s}$. This non-uniform temperature distribution inside the nanofluid is primarily caused by the localized solar energy input of $500 \mathrm{~kW} / \mathrm{m}^{2}$ at the focal point. Consequently, the temperature attains the boiling point rapidly, which explains the generation of steam despite certain parts of the nanofluid being subcooled. This has been discussed in our previous research on the impossibility of nanobubbles [10]. The steam temperature indicated by T6 and T7 in this study increases sharply when the temperature of most parts of the nanofluid attains the boiling point. This occurs after approximately $230 \mathrm{~s}$ when pool boiling transpires and generates steam efficiently at this stage. Section 3.5 discusses the energy consumption of bulk volume heating and steam generation further.

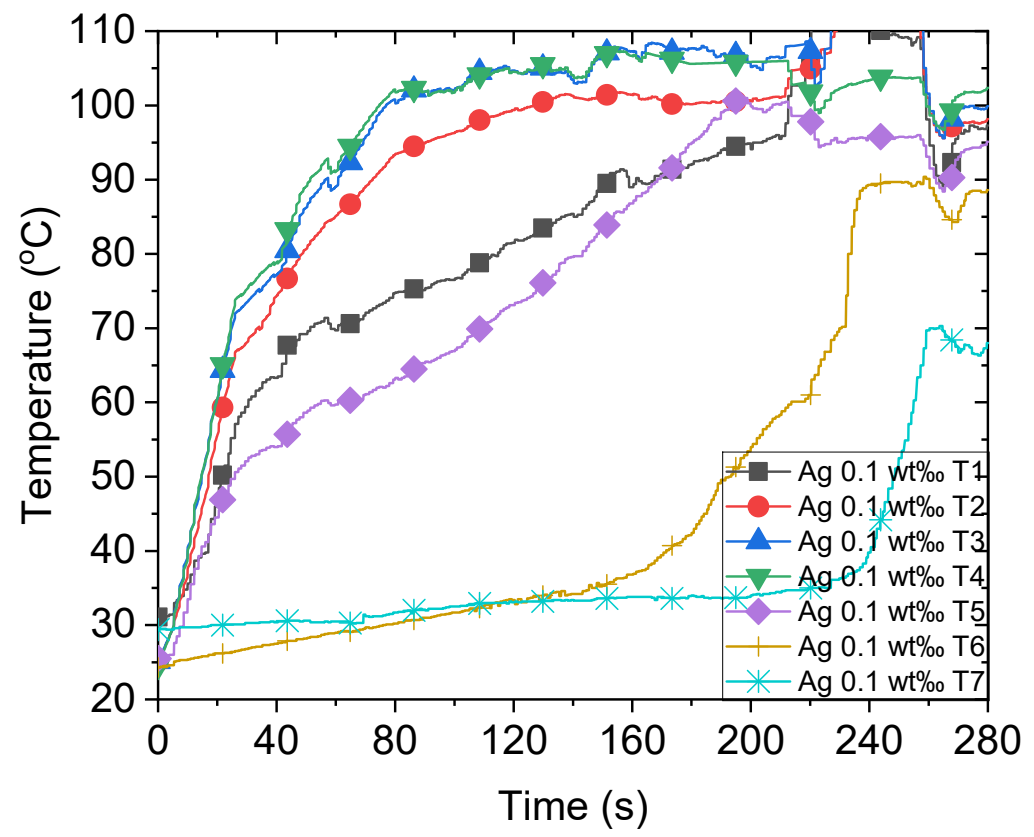

Figure 3. Temperature variations of $0.1 \mathrm{wt} \%$ Ag nanofluid under concentrated sunlight of 500 suns.

\subsection{Effect of Nanofluid Concentrations on Solar Energy Absorption Performance}

According to the radiative heat transfer theory [48], the photothermal conversion performance of the working fluid can remarkably change by adding a few nanoparticles. Figure 4 depicts the temperatures of different concentrations of Ag nanofluid tested in this study. When highly diluted Ag nanofluids (Figure 4A,B with concentrations of 0.01 wt \%o and $0.02 \mathrm{wt} \%$, respectively) are illuminated under concentrated sunlight, the bulk temperature of the nanofluid increases slower than that of the highly concentrated nanofluid (Figure $4 \mathrm{D}$ with a concentration of $0.2 \mathrm{wt} \%$ ). Additionally, the temperature of steam (T6 and T7) in the $0.02 \mathrm{wt} \% \mathrm{Ag}$ nanofluid is approximately $100{ }^{\circ} \mathrm{C}$ at $240 \mathrm{~s}$, whereas that of the $0.01 \mathrm{wt} \%$ o $\mathrm{Ag}$ nanofluid is not close to the boiling point. This can be attributed to the 
increase in photothermal conversion efficiency with the increase in the concentration of nanofluids, which in turn accelerates the steam generation rate after the bulk temperature attains the boiling point. Therefore, increasing the concentration of a nanofluid accelerates the heating of the bulk fluid owing to the sunlight and enhances the steam generation efficiency (Section 3.5). Interestingly, when the concentration of Ag nanofluid attained a certain level $(0.2 \mathrm{wt} \%)$, the temperature profile increased more uniformly at the heating stage, as illustrated in the initial $40 \mathrm{~s}$ in Figure 4D. Furthermore, steam generation occurs at approximately $200 \mathrm{~s}$ when the bulk temperature attains the boiling point uniformly and the nanofluid starts bubbling violently, which is discussed in Section 3.4.
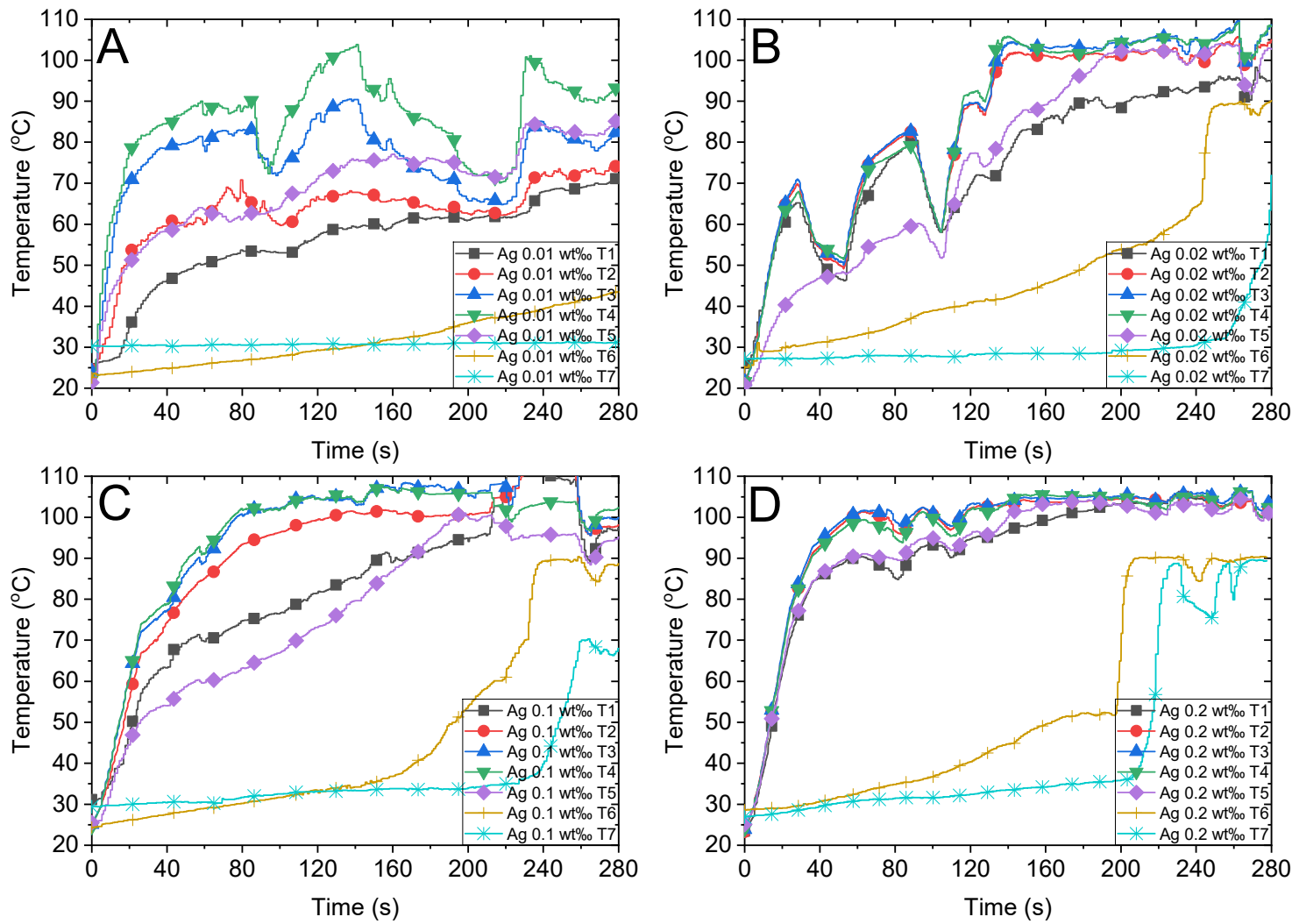

Figure 4. Temperature variations of Ag nanofluid with different concentrations and the air above the fluid under concentrated sunlight of 500 suns. Ag nanofluid with mass fractions of (A) $0.01 \mathrm{wt} \%$, (B) $0.02 \mathrm{wt} \%$, (C) $0.1 \mathrm{wt} \%$ and (D) $0.2 \mathrm{wt} \%$.

\subsection{Effect of Different Nanofluids on Solar Energy Absorption Performance}

To further understand the influence of material characteristics on the performance of solar harvesting and steam generation, we used the Mie scattering model [48] to investigate the absorption efficiency of solar radiation. In the existing model, the characteristic size in the following equations is calculated as $x_{\lambda}=\pi D / \lambda$, where $D$ is the size of nanoparticles. The following original Mie scattering equations are employed.

$$
\begin{gathered}
a_{n}=\frac{m \psi_{n}(m x) \psi_{n}{ }^{\prime}(x)-\psi_{n}(x) \psi_{n}{ }^{\prime}(m x)}{m \psi_{n}(m x) \xi_{n}{ }^{\prime}(x)-\xi_{n}(x) \psi_{n}{ }^{\prime}(m x)} \\
b_{n}=\frac{\psi_{n}(m x) \psi_{n}{ }^{\prime}(x)-m \psi_{n}(x) \psi_{n}{ }^{\prime}(m x)}{\psi_{n}(m x) \xi_{n}{ }^{\prime}(x)-m \xi_{n}(x) \psi_{n}{ }^{\prime}(m x)} \\
Q_{s c a}(\lambda)=\frac{2}{x^{2}} \sum_{n=1}^{\infty}(2 n+1)\left[\left|a_{n}\right|^{2}+\left|b_{n}\right|^{2}\right]
\end{gathered}
$$




$$
\begin{gathered}
Q_{e x t}(\lambda)=\frac{2}{x^{2}} \sum_{n=1}^{\infty}(2 n+1) \operatorname{Re}\left(a_{n}+b_{n}\right) \\
Q_{\mathrm{abs}}=Q_{\mathrm{ext}}-Q_{\mathrm{sca}}
\end{gathered}
$$

where the functions $\psi_{n}(x)$ and $\zeta_{n}(x)$ denote the spherical Bessel functions [48] of order $\mathrm{n}(n=1,2 \ldots)$, the primes represent the derivatives with respect to the argument, and $\mathrm{m}$ indicates the ratio of refractive indices calculated using

$$
\mathrm{m}=\frac{n_{\text {particles }}}{n_{\text {fluid }}}
$$

where $n_{\text {particles }}$ and $n_{\text {fluid }}$ denote the complex refractive indices [49] of particle material and base fluid (water) relative to the ambient medium, respectively. Considering the relatively low concentrations of nanofluids used for solar thermal applications, particles should absorb and scatter light independently based on the scattering map [48].

The solar harvesting efficiency of nanofluid relays on its optical properties. Typically, the photothermal conversion efficiency of sunlight varies for different nanofluids of identical concentrations owing to distinct radiative heat transfer characteristics. As depicted in Figure 5B, the absorption factors of different nanofluids vary in terms of wavelength with distinct peak efficiency factors. Although the peak absorption factor of Ag nanoparticles of diameter $20 \mathrm{~nm}$ is more than 14, the efficient absorption efficiency of solar radiation may be lower than that of Au nanoparticles with the same diameter. This is because the solar spectra emissive power peaks at approximately $500 \mathrm{~nm}$, which is close to the peak absorption factor of Au nanoparticles. Hence, the absorption efficiency of Au nanofluid is higher than that of Ag nanofluid, which has been investigated in our previous research [21]. Figure 6B illustrates the steam temperature of the $0.02 \mathrm{wt} \%$ ou nanofluid attaining the steady state after approximately $130 \mathrm{~s}$, indicating efficient vapor generation. Conversely, the steam temperature of the Ag nanofluid with the same concentration is relatively low despite the temperature of certain parts of the volume attaining the boiling point (Figure 4B).
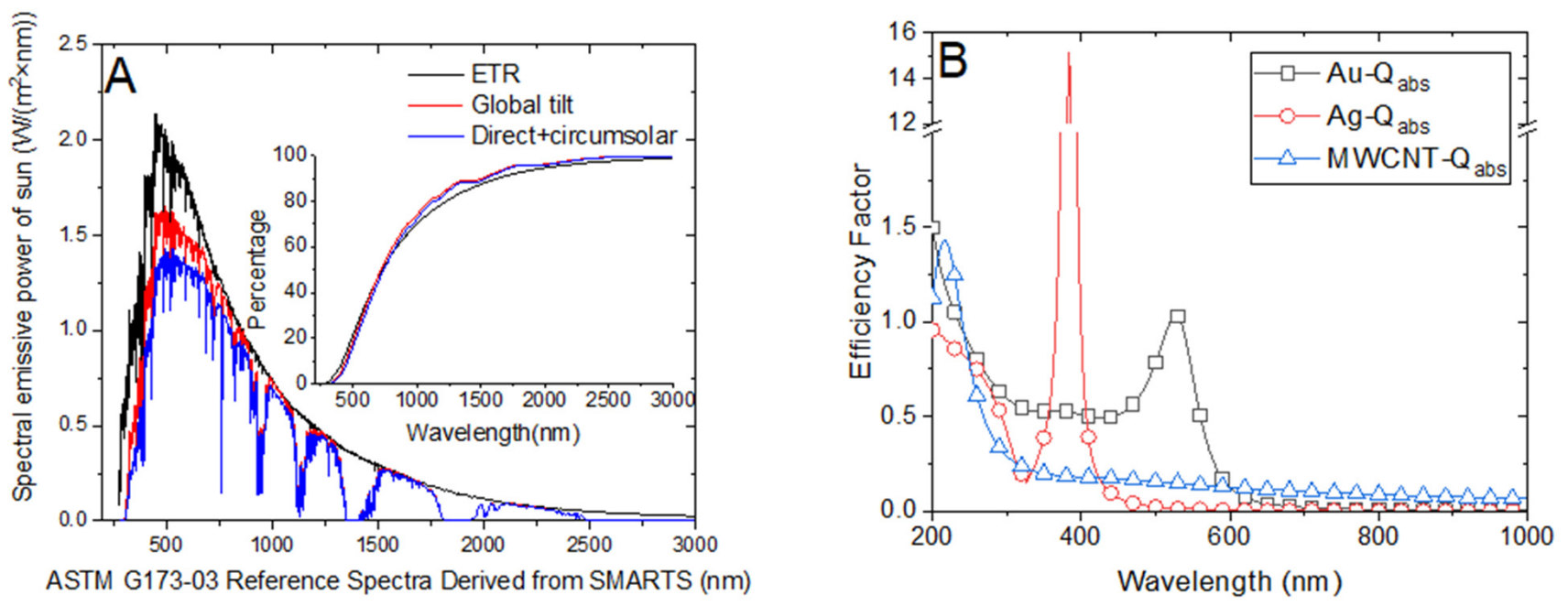

Figure 5. (A) ASTM G173-03 reference solar spectra emissive power with respect to wavelength. (B) Absorption factors of $\mathrm{Au}, \mathrm{Ag}$, and multiwalled carbon nanotube (MWCNT) nanoparticles. 

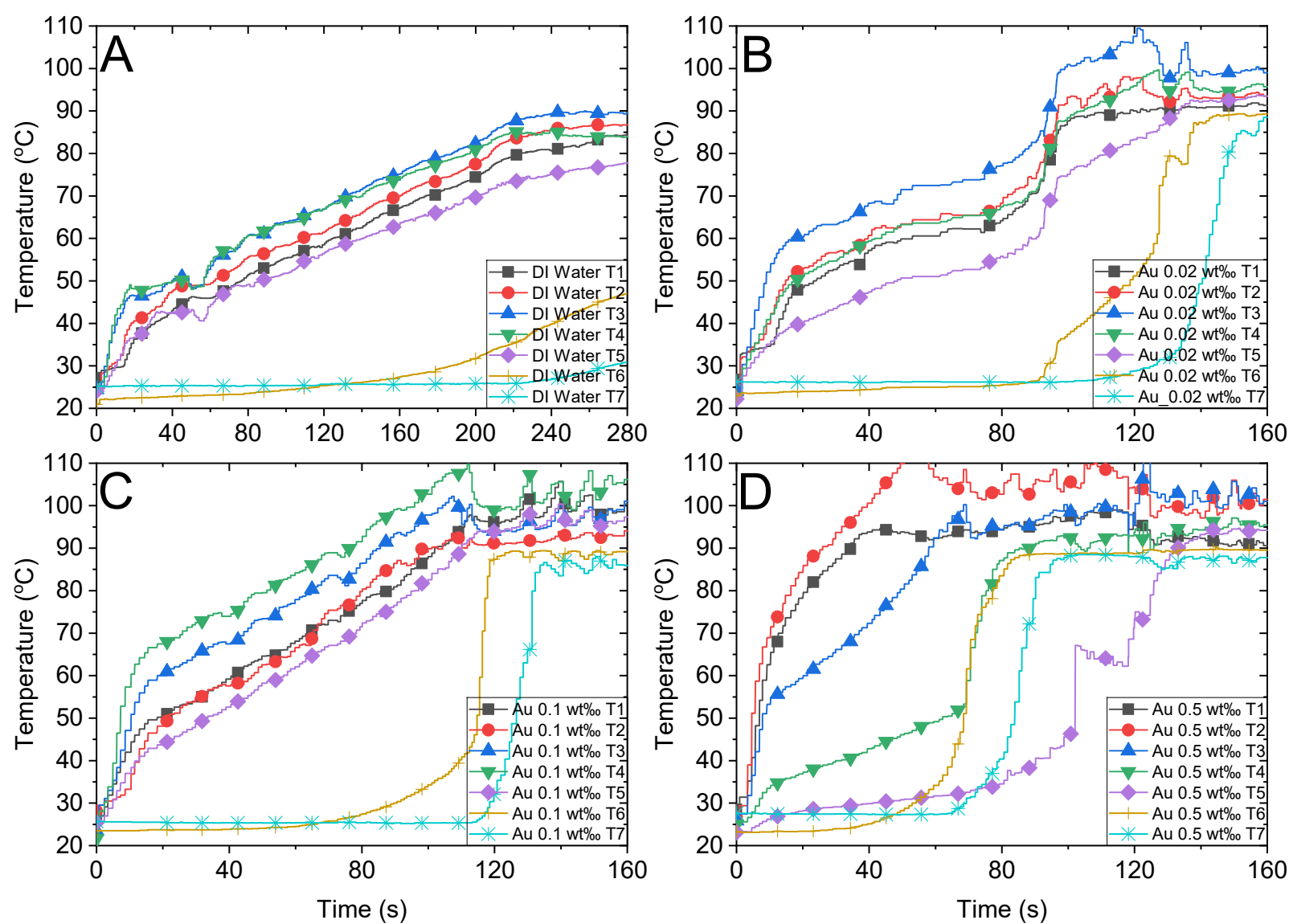

Figure 6. Temperature variations of water, Au nanofluid with different concentrations, and the air above the fluid under concentrated sunlight of 500 suns. (A) Deionized water. Au nanofluid with mass fractions of (B) $0.02 \mathrm{wt} \%$, (C) $0.1 \mathrm{wt} \%$ and (D) $0.5 \mathrm{wt} \%$.

As depicted in Figure 6A, the maximum temperature attained by the DI water is less than $90^{\circ} \mathrm{C}$ after illumination of $280 \mathrm{~s}$, and the temperature appears to reach a steady state subsequently. The energy absorbed from the solar radiation equilibrates with the convective heat loss when the ambient temperature is high. Although it is difficult for the DI water to attain the boiling point under existing experimental settings, the bulk temperatures of all other nanofluids attained boiling points.

Figure 5B illustrates the absorption factor of the MWCNT nanofluid, which exhibits a flat variation along the spectrum wavelength and is relatively lower than that of $\mathrm{Au}$ nanoparticles. We compared the steam temperatures of $0.5 \mathrm{wt} \% \mathrm{Au}$ and $0.4 \mathrm{wt} \% \mathrm{MWCNT}$ depicted in Figures 6D and 7B, respectively, as the mass concentrations are nearly identical. We observed that the steam temperature attains a steady state after approximately $80 \mathrm{~s}$ and $130 \mathrm{~s}$ in the case of $\mathrm{Au}$ and MWCNT nanofluids, respectively. If the concentration of MWCNT nanofluid increases to a certain level $(1.6 \mathrm{wt} \%$ ), the bulk temperature drastically increases to the boiling point, efficiently generating steam after approximately $100 \mathrm{~s}$. Although the heating process of MWCNT nanofluid was substantially faster than that of Au nanofluid, the generation of steam was slightly slow as the former required $100 \mathrm{~s}$, whereas the latter required $80 \mathrm{~s}$ to generate steam. This is associated with the volume expansion and concentration dilution when illuminated by solar radiation, which is discussed in Section 3.4. 

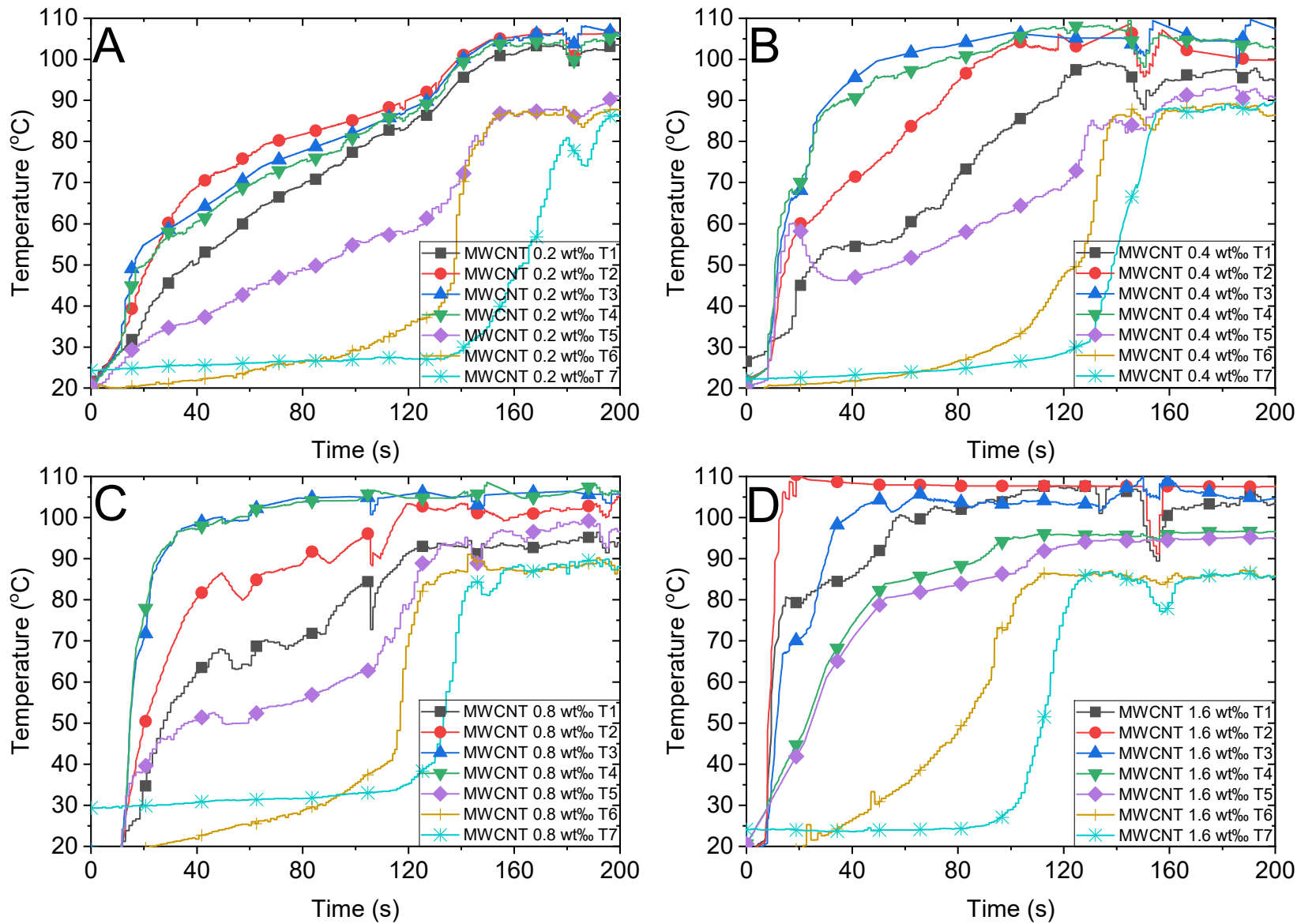

Figure 7. Temperature variations of the multiwalled carbon nanotube (MWCNT) nanofluid with different concentrations and the air above the fluid under concentrated sunlight of 500 suns. MWCNT with mass fractions of (A) $0.2 \mathrm{wt} \%$, (B) 0.4 $\mathrm{wt} \%$, (C) $0.8 \mathrm{wt} \%$ and (D) $1.6 \mathrm{wt} \%$.

\subsection{Temperature Distribution and Bubble Formation in Different Nanofluids}

\subsubsection{Ag Nanofluid}

Figure 8 depicts the bubble formation process and infrared images of Ag nanofluid with different concentrations captured under concentrated sunlight. As illustrated in Figure 8A, the bubble formation in low concentration Ag nanofluid $(0.01 \mathrm{wt} \%$ o occurs after $165 \mathrm{~s}$, and the temperature increment is relatively slow. During the entire testing process, the steam temperature represented by the infrared image was maintained low owing to the high transparency of the sunlight. Additionally, the bubble formation turned more violent when the mass concentration increased. Figure $8 \mathrm{~B}$ depicts the generation of numerous small bubbles in the $0.02 \mathrm{wt} \%$ og nanofluid after $130 \mathrm{~s}$. However, although the boing point was attained after $40 \mathrm{~s}$ (Figure 8B), only a few bubbles were observed. This is similar to the initial process of pool boiling, wherein the localized heat input was responsible for the temperature attaining the boiling point at the focal area.

\subsubsection{Au Nanofluid}

Figure 9 depicts the bubble formation process of DI water and Au nanofluids of various concentrations. In the case of DI water, the temperature of the working fluid increases slowly and no bubbles generate until $240 \mathrm{~s}$, as illustrated in Figure 8A. Conversely, the temperature increases rapidly in Au nanofluids, and the working fluids of all three concentrations begin to generate bubbles within $90 \mathrm{~s}$. Furthermore, adding a small number of nanoparticles to the water can improve its photothermal conversion efficiency significantly, which increases with the concentration of nanofluids. Moreover, for high concentrations 
of Au nanofluids, such as $0.1 \mathrm{wt} \%$ and $0.5 \mathrm{wt} \%$, it can enter the stage of violent bubble generation within $90 \mathrm{~s}$ and the temperature of the steam reaches approximately $90{ }^{\circ} \mathrm{C}$.

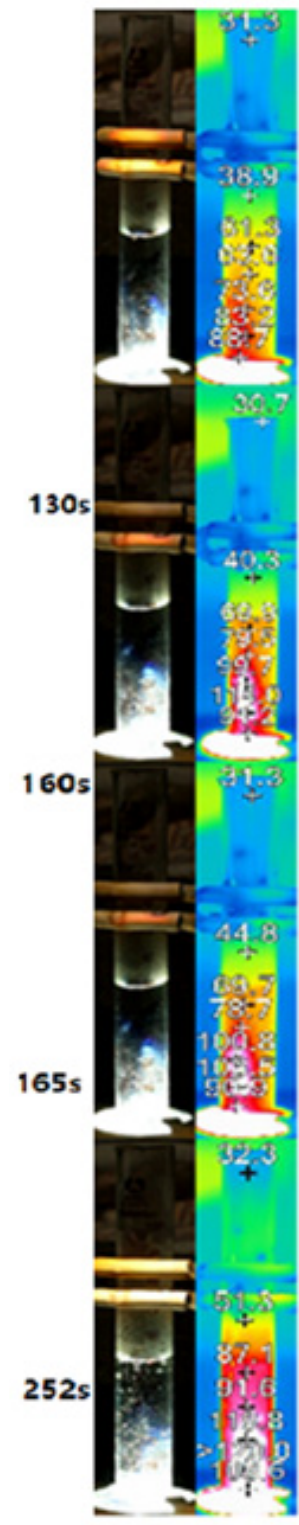

$\mathbf{A}$

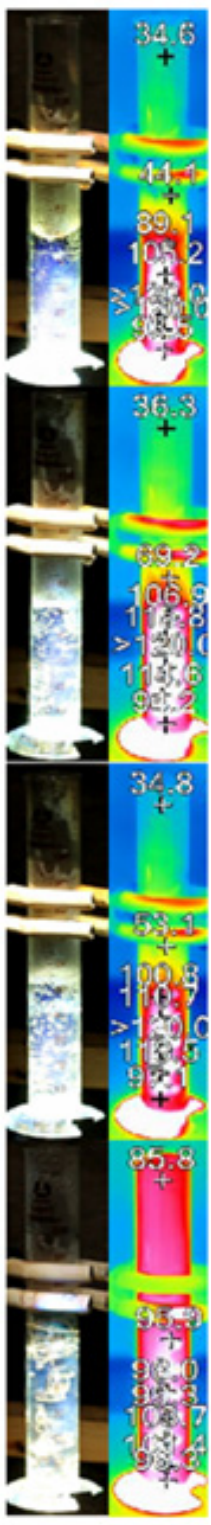

B

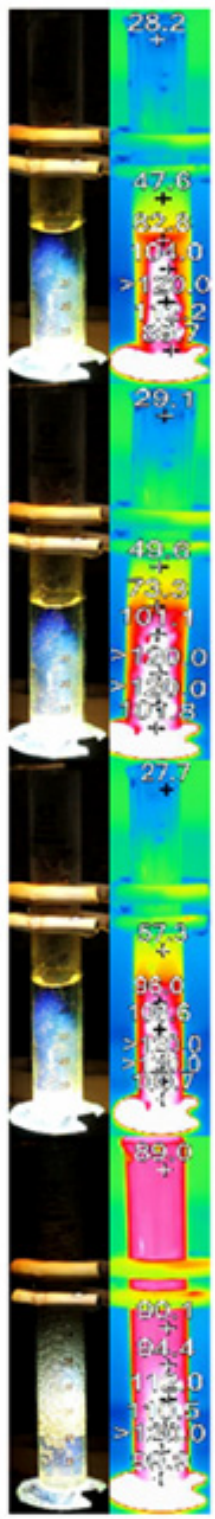

C

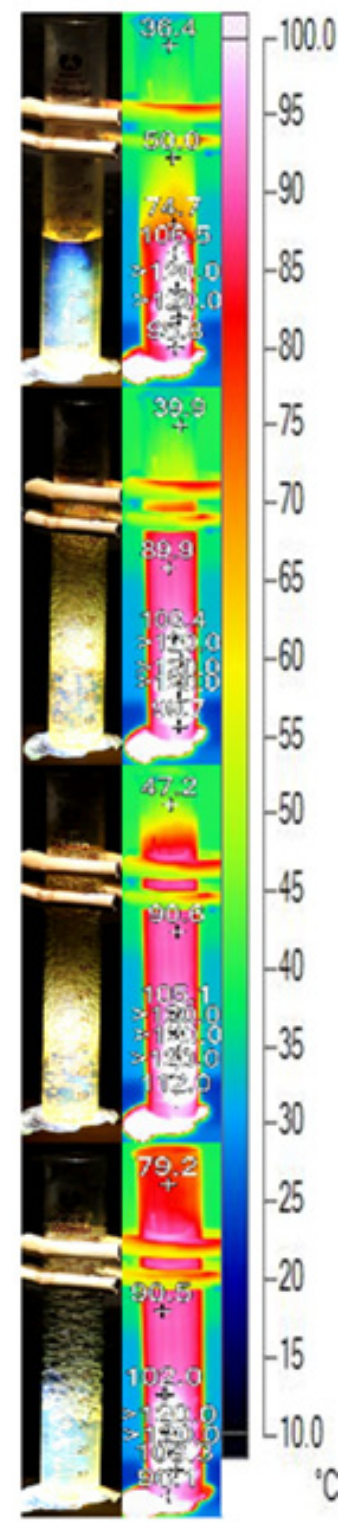

D

Figure 8. Bubble formation and infrared images of Ag nanofluid under concentrated solar radiation. Ag nanofluid of concentrations (A) $0.01 \mathrm{wt} \%$, (B) $0.02 \mathrm{wt} \%$, (C) $0.1 \mathrm{wt} \%$ and (D) $0.2 \mathrm{wt} \%$.

\subsubsection{MWCNT Nanofluid}

Figure 10 illustrates the bubble formation process of different concentrations of MWCNT nanofluid under concentrated sunlight. We observed that all concentrations of MWCNT nanofluids attained the highest temperature above $120^{\circ} \mathrm{C}$, which is $20^{\circ} \mathrm{C}$ higher than the boiling temperature of the water, within $44 \mathrm{~s}$. Additionally, the internal temperature of the fluid varied significantly. However, although the internal temperature reached the boiling point or higher temperatures, the phenomenon of bubble formation was not observed. This is consistent with the conclusion obtained in Section 3.3, wherein the bubble generation in MWCNT nanofluid was slower than that of Au nanofluid despite the rapid increase in temperature. Furthermore, we observed a volume expansion in the $1.6 \mathrm{wt} \%$ MWCNT nanofluid when illuminated by the concentrated solar radiation. 
This causes the calculation error in the energy consumption of steam generation, which is discussed in Section 3.5. The volume increase can be attributed to the high concentration of nanoparticles within the fluid.

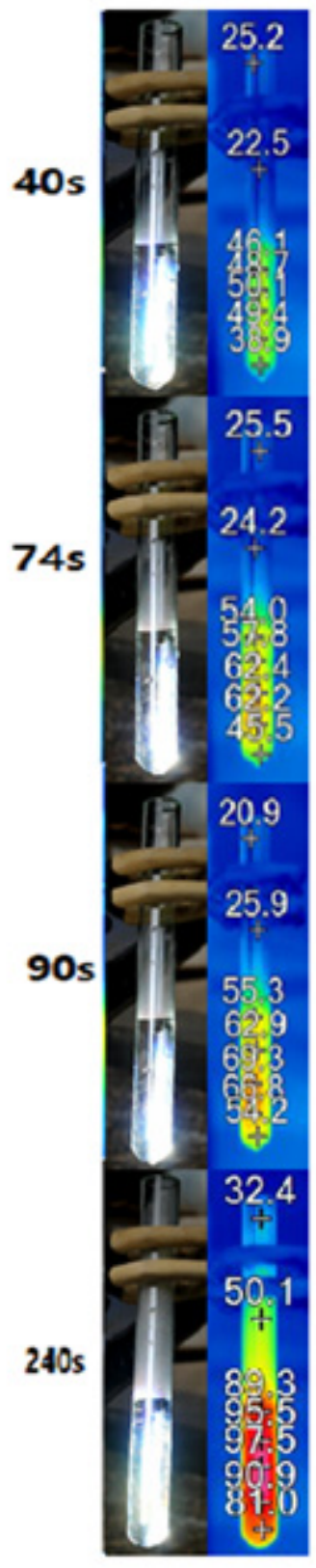

A

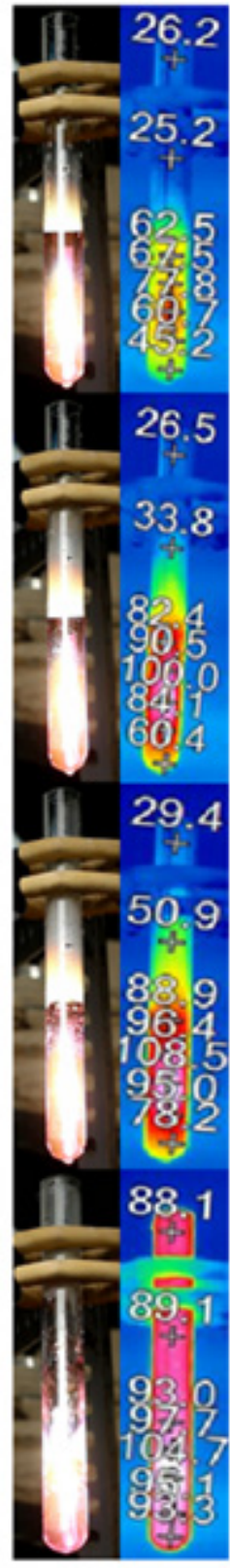

B

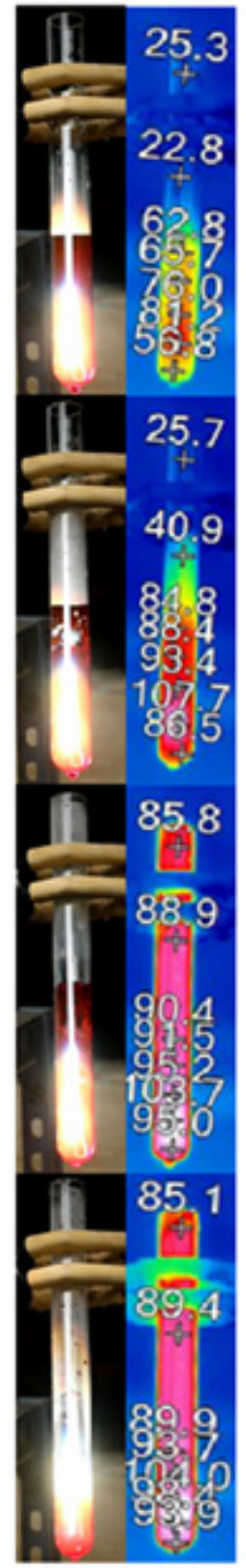

C

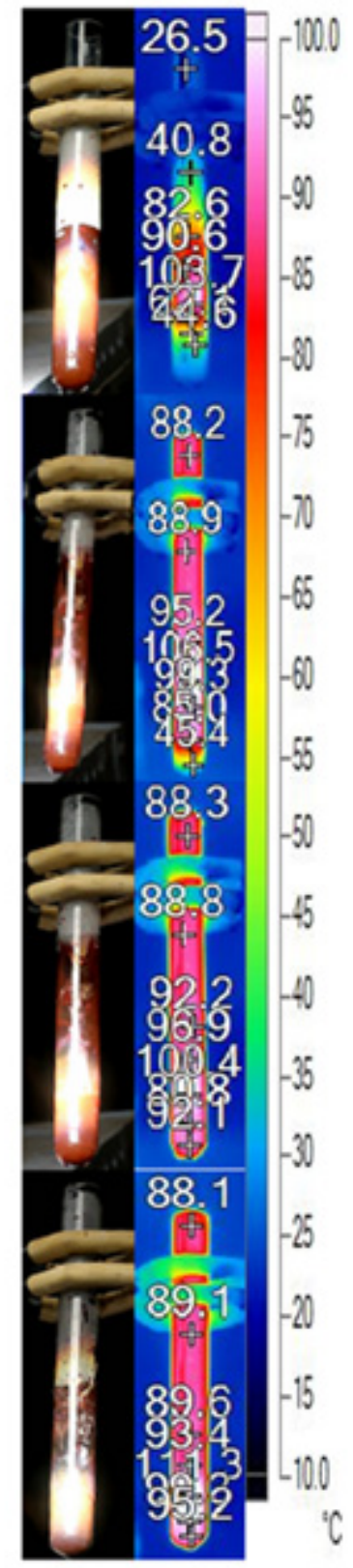

D

Figure 9. Bubble formation and infrared images of (A) deionized water and Au nanofluid of concentrations (B) $0.02 \mathrm{wt} \%$, (C) $0.1 \mathrm{wt} \%$ and (D) $0.5 \mathrm{wt} \%$ o under solar radiation.

\subsection{Energy Harvesting and Efficiency Analysis}

Figure 11 illustrates the volume variations of DI water and Au nanofluid of different concentrations under concentrated sunlight. As the experiment progressed, the internal temperature of the working fluid continued to increase, generating bubbles that escaped from the fluid and thereby reducing its volume. As the concentration of nanofluid increased, the working fluid generated steam earlier, and the rate of steam generation was higher. This is because an increase in the concentration of nanofluids increases the solar thermal conversion efficiency of the working fluid. In other words, the working fluid receives more 
heating power, and higher power is required to overcome the latent heat when the rate of bubble generation is high. However, it is not clear whether the proportion of power used for latent heat increases with the increase in the heating power. This implies that more power is consumed to generate bubbles. This is discussed further after calculating the energy consumption.

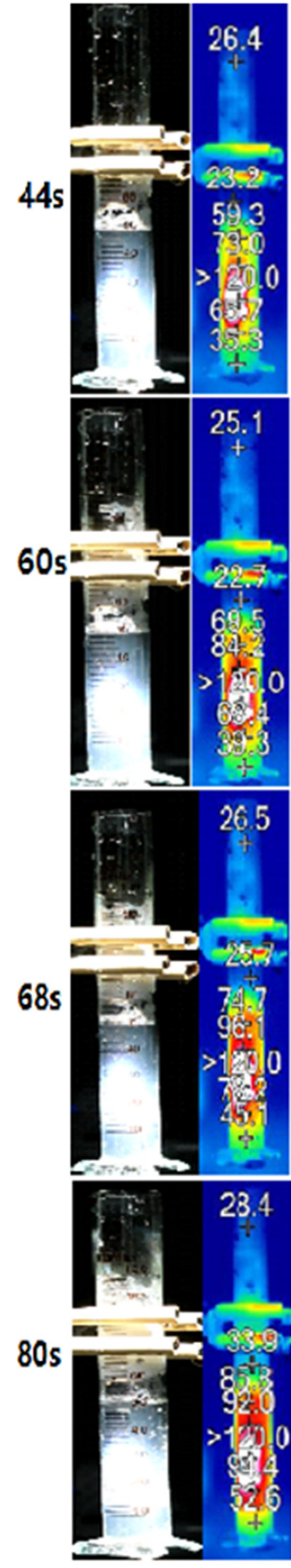

A
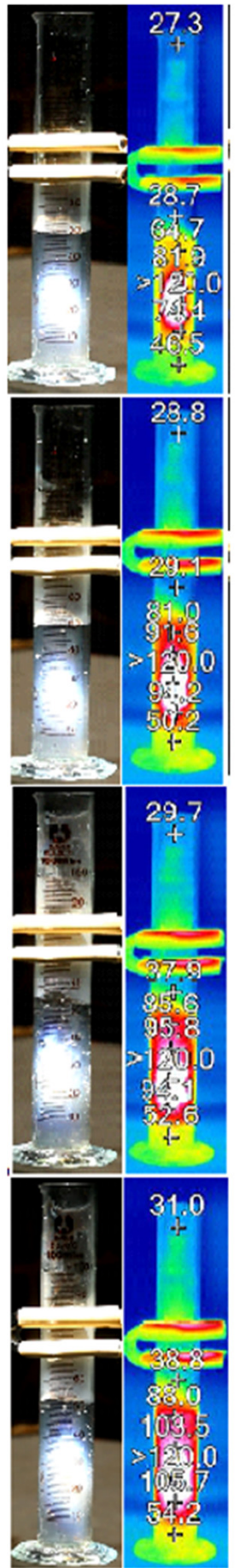

B
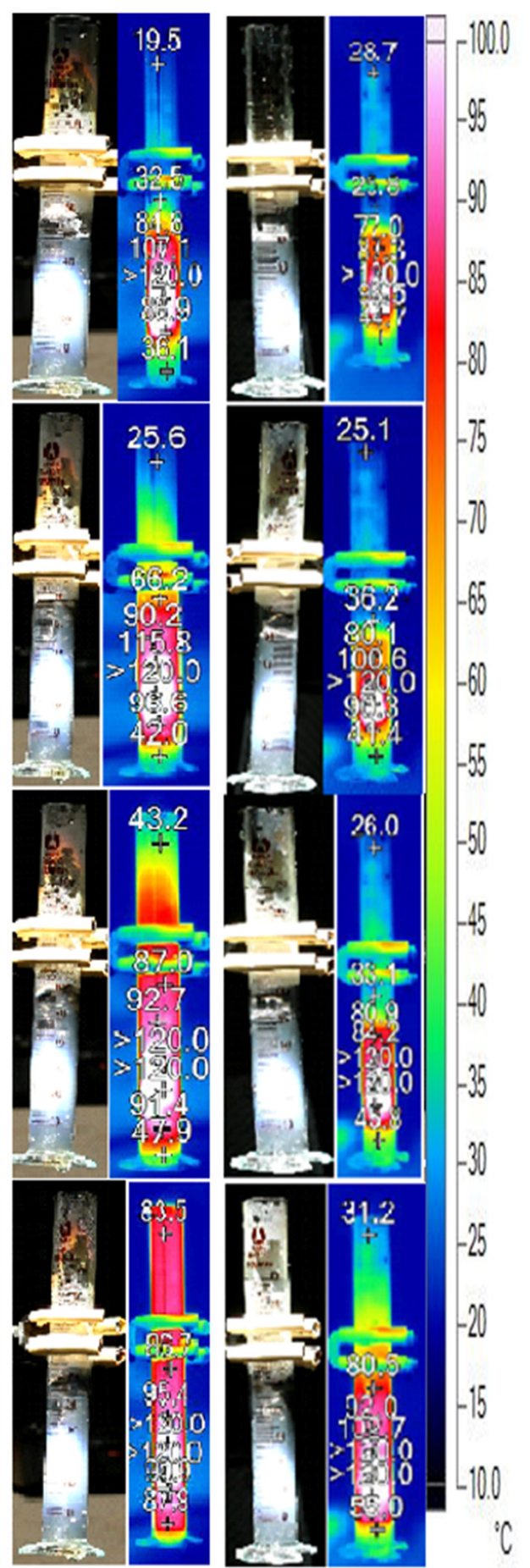

$\mathrm{C}$

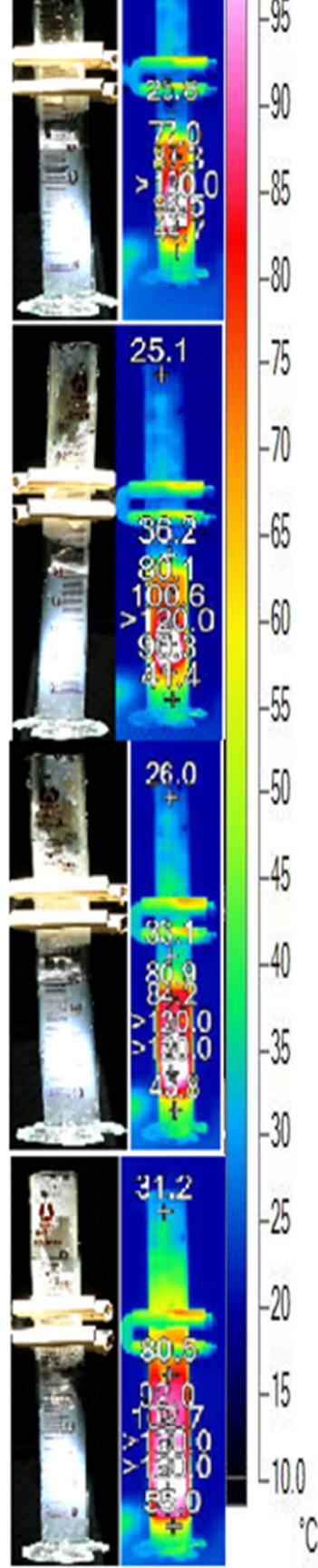

$\mathrm{D}$

Figure 10. Bubble formation and infrared images of multiwalled carbon nanotube (MWCNT) nanofluid under concentrated solar radiation. MWCNT nanofluid of concentrations (A) $0.2 \mathrm{wt} \%$, (B) $0.4 \mathrm{wt} \%$, (C) $0.8 \mathrm{wt} \%$ and (D) $1.6 \mathrm{wt} \%$. 


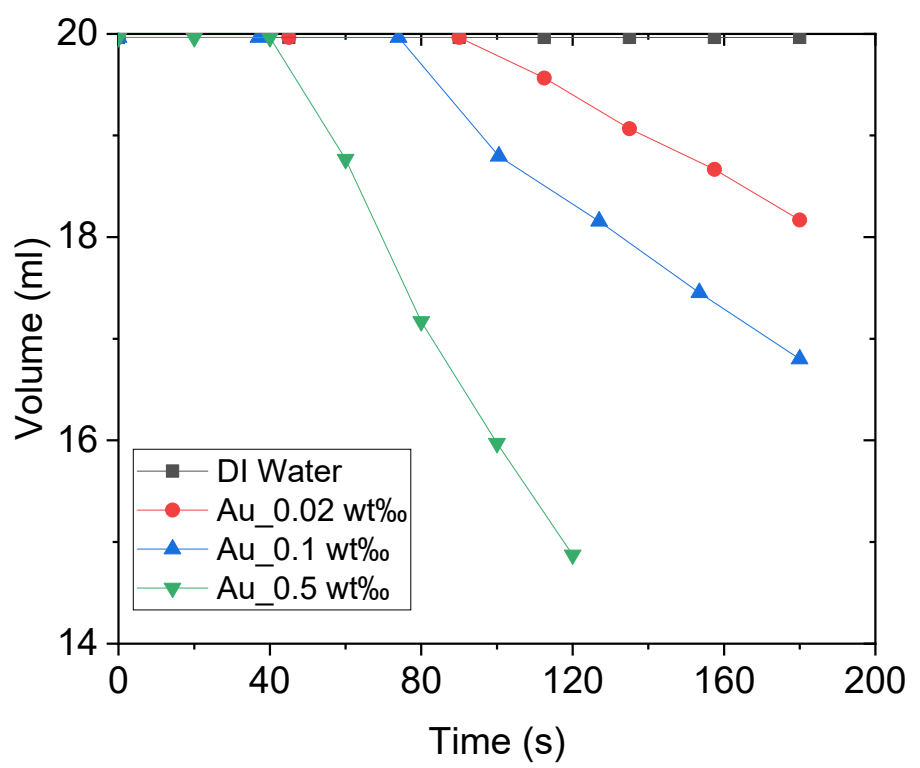

Figure 11. Volume variations of deionized water and Au nanofluid of concentrations $0.02 \mathrm{wt} \%$, $0.1 \mathrm{wt} \%$, and $0.5 \mathrm{wt} \%$.

The latent heat power and sensible heat power of the working fluid in the experiment can be calculated using the following equations.

$$
\begin{gathered}
P_{\text {sensible }}=\left(c_{w} m_{w}+c_{n} m_{n}\right) \Delta \bar{T} / t \approx c_{w} m_{w} \Delta \bar{T} / t=c_{w} m_{w} \sum_{\mathrm{n}=1}^{\mathrm{n}=5} \Delta T_{\mathrm{n}} / 5 t \\
\frac{U_{P_{\text {sensible }}}}{P_{\text {sensible }}}=\sqrt{\left(\frac{U_{m}}{m_{w}}\right)^{2}+5\left(\frac{U_{T}}{\sum_{\mathrm{n}=1}^{\mathrm{n}=5} \Delta T_{\mathrm{n}}}\right)^{2}} \\
P_{\text {steam }}=\mathrm{L} \Delta \dot{m}_{w}=\mathrm{L} \Delta m_{w} / t \\
U_{P_{\text {steam }}}=\mathrm{L} U_{m} / t \\
P_{\text {heat }}=P_{\text {sensible }}+P_{\text {steam }} \\
U_{P_{\text {heat }}}=\sqrt{U_{P_{\text {sensible }}{ }^{2}+U_{P_{\text {steam }}{ }^{2}}^{2}}}
\end{gathered}
$$

where, $m_{w}$ and $m_{n}$ denote the masses of water and nanoparticles, respectively, and L represents the latent heat of evaporation of water. The power of each group of experiments can be obtained via calculations. Figure 12 depicts the heating power (increasing the temperature) and steam generation power of DI water and Au nanofluid of various concentrations. The heating power and steam generation power increase with the nanofluid concentration, which is consistent with the results of our previous studies [10,12]. The heating power of Au nanofluid with concentration of $0.5 \mathrm{wt} \%$ is around 6 times higher than that of pure water. What's interesting, for the same nanofluid, the absorbed solar energy for steam generation is $143.88 \mathrm{~W}$, which is more than 40 times higher than that of pure water (i.e., $3 \mathrm{~W}$ ). Furthermore, the ratio of latent heat power to heating power gradually increases with the increasing concentration, which indicates that the increase in nanofluid concentration renders the steam generation easier. This can be closely associated with heat loss, which is relatively large when the heating power applied to the nanofluid is high. Additionally, the convective and radiative heat losses increase with the increase in temperature. 


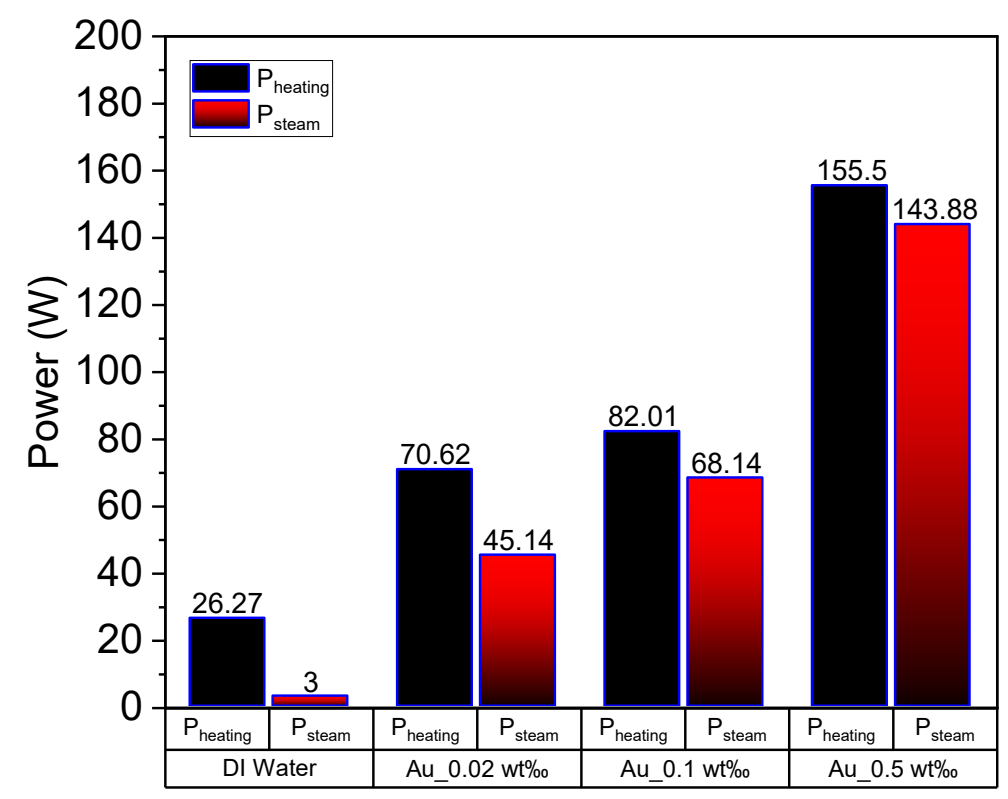

Figure 12. Heating power and latent heat power of deionized water and Au nanofluid of concentrations $0.02 \mathrm{wt} \%$, $0.1 \mathrm{wt} \%$ and $0.5 \mathrm{wt} \%$.

Figure 13 depicts the calculated heating power and steam generation power of MWCNT nanofluids under concentrated sunlight. Herein, the behavior of energy consumption is different from that observed in Au nanofluids. The heating power of the working fluid increases as the concentration increases, as illustrated in Figure 13. However, the latent heat power $\left(\mathrm{P}_{\text {steam }}\right)$ increases slightly with the increase in concentration, although the latent heat power of $1.6 \mathrm{wt} \%$ MWCNT nanofluid is lower than that of $0.8 \mathrm{wt} \%$ MWCNT nanofluid. This is because when the concentration of MWCNT is extremely high, the volume expansion cannot be ignored when illuminated under concentrated solar radiation, as mentioned in Section 3.4. Additionally, the steam generation power was calculated based on the volume reduction of the fluid, which was underestimated in the current experiment.

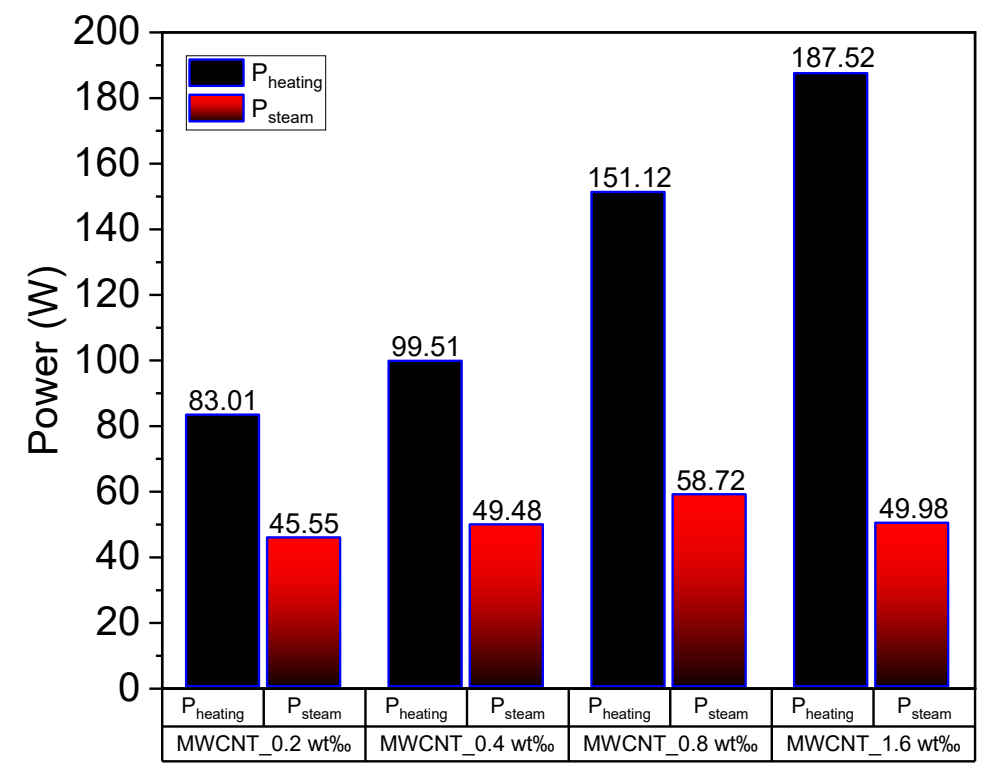

Figure 13. Heating power and latent heat power of multiwalled carbon nanotube (MWCNT) nanofluid of concentrations $0.2 \mathrm{wt} \%$ o, $0.4 \mathrm{wt} \%$, $0.8 \mathrm{wt} \%$ and $1.6 \mathrm{wt} \%$. 
Based on the comparison of volume heating and steam generation efficiency of different nanofluids, we determined that the Au and Ag nanofluids can absorb solar energy efficiently when the concentration is low. However, the concentration of MWCNT nanofluid needs to be extremely high to have the same performance, which can be attributed to the efficiency factor calculated in Section 3.4. Moreover, the volume expansion dilutes the concentration of MWCNT nanofluid when the concentration is high. This requires further investigations in the future.

It's natural to wonder if the cost of the nanomaterial can fit the energy outcome. As introduce in our previous work [50], the cost of nanoparticles for each kilo nanofluid producing each $\mathrm{kW}$ thermal energy has been calculated through the equation below:

$$
\text { Cost }=\frac{C \cdot \operatorname{Cost}_{n p}}{P}
$$

where $\operatorname{Cost}_{n p}(\$ / \mathrm{kg})$ is the cost of $1 \mathrm{~kg}$ of the nanoparticles. Overall, $\$ 43,000$ is used for gold nanoparticles, which represents the price of gold in the global stocks market, and $\$ 180$ is used for carbon-based nanoparticles, which represents the supplier price. $C$ is the mass concentration of nanofluids, $P$ is the steam generation power. For Au nanofluid with mass concentration of $0.1 \mathrm{wt} \%$, Cost $=63(\$ /(\mathrm{kg} \cdot \mathrm{kW}))$. For MWCNT nanofluid with mass concentration of $0.2 \mathrm{wt} \%$, Cost $=0.79(\$ /(\mathrm{kg} \cdot \mathrm{kW}))$. It can be concluded that even the steam generation efficiency for Au nanofluids is high, and the cost is still high when compared with carbon based nanomaterial.

\section{Conclusions}

To investigate the effective generation of steam, $\mathrm{Ag}$, $\mathrm{Au}$, and MWCNT nanofluids of different concentrations were prepared and illuminated under concentrated solar radiation. The temperature distribution was recorded using an infrared camera, whereas the volume change and bubble formation process were captured using a high-speed camera. Additionally, we investigated the increase in temperature and steam generation combined with radiative heat transfer calculation of the efficiency factor. The heating power and steam generation power of different nanofluids and the same nanofluid with different concentrations were compared. The conclusions of our analysis can be summarized as follows.

(1) The temperature increases rapidly under concentrated solar radiation when the concentration of the nanofluids increase. Typically, steam generates excessively when the bulk temperature attains the boiling point in the case of different nanofluids.

(2) The volume heating and steam generation efficiency vary for different nanofluids with identical concentrations, which can be attributed to the efficiency factor of different nanoparticles. The absorbed solar energy for heating the volume and generating steam is 6 and 40 times higher than those of pure water, respectively, when the Au nanofluid concentration is $0.5 \mathrm{wt} \%$.

(3) The bubble formation initiates at the focal point under concentrated solar radiation, indicating the localized boiling that causes the rapid steam generation of nanofluids.

(4) The heating power and steam generation power of different nanofluids increase with concentration. However, an extremely high concentration of MWCNT nanofluids is not recommended for efficient steam generation owing to the volume expansion, which requires further investigations in the future.

Author Contributions: Conceptualization, X.J. and H.J.; writing-review and editing, H.J.; supervision, G.L. All authors have read and agreed to the published version of the manuscript.

Funding: This work was supported by the National Natural Science Foundation of China [grant number 51906010] and the National Numerical Wind Tunnel [grant number 2018-ZT3A05].

Conflicts of Interest: The authors declare no conflict of interest. 


\section{References}

1. Tian, Y.; Zhao, C.Y. A review of solar collectors and thermal energy storage in solar thermal applications. Appl. Energy 2013, 104, 538-553. [CrossRef]

2. Elimelech, M.; Phillip, W.A. The Future of Seawater Desalination: Energy, Technology, and the Environment. Science 2011, 333, 712-717. [CrossRef]

3. Shannon, M.A.; Bohn, P.W.; Elimelech, M.; Georgiadis, J.G.; Marinas, B.J.; Mayes, A.M. Science and technology for water purification in the coming decades. Nature 2008, 452, 301-310. [CrossRef]

4. Tiwari, G.N.; Singh, H.N.; Tripathi, R. Present status of solar distillation. Solar Energy 2003, 75, 367-373. [CrossRef]

5. Gupta, M.K.; Kaushik, S.C. Exergy analysis and investigation for various feed water heaters of direct steam generation solarthermal power plant. Renew. Energy 2010, 35, 1228-1235. [CrossRef]

6. Yu, S.; Zhang, Y.; Duan, H.; Liu, Y.; Quan, X.; Tao, P.; Shang, W.; Wu, J.; Song, C.; Deng, T. The impact of surface chemistry on the performance of localized solar-driven evaporation system. Sci. Rep. 2015, 5, 13600. [CrossRef]

7. Shannon, M.A. Water desalination Fresh for less. Nat. Nanotechnol. 2010, 5, 248-250. [CrossRef]

8. Ghasemi, H.; Ni, G.; Marconnet, A.M.; Loomis, J.; Yerci, S.; Miljkovic, N.; Chen, G. Solar steam generation by heat localization. Nat. Commun. 2014, 5, 4449. [CrossRef]

9. Bae, K.; Kang, G.; Cho, S.K.; Park, W.; Kim, K.; Padilla, W.J. Flexible thin-film black gold membranes with ultrabroadband plasmonic nanofocusing for efficient solar vapour generation. Nat. Commun. 2015, 6, 10103. [CrossRef]

10. Jin, H.C.; Lin, G.P.; Bai, L.Z.; Zeiny, A.; Wen, D.S. Steam generation in a nanoparticle-based solar receiver. Nano Energy 2016, 28, 397-406. [CrossRef]

11. Jin, H.C.; Lin, G.P.; Bai, L.Z.; Amjad, M.; Bandarra, E.P.; Wen, D.S. Photothermal conversion efficiency of nanofluids: An experimental and numerical study. Solar Energy 2016, 139, 278-289. [CrossRef]

12. Jin, H.C.; Lin, G.P.; Zeiny, A.; Bai, L.Z.; Wen, D.S. Nanoparticle-based solar vapor generation: An experimental and numerical study. Energy 2019, 178, 447-459. [CrossRef]

13. Khullar, V.; Tyagi, H.; Hordy, N.; Otanicar, T.P.; Hewakuruppu, Y.; Modi, P.; Taylor, R.A. Harvesting solar thermal energy through nanofluid-based volumetric absorption systems. Int. J. Heat Mass Transf. 2014, 77, 377-384. [CrossRef]

14. Ishii, S.; Sugavaneshwar, R.P.; Nagao, T. Titanium Nitride Nanoparticles as Plasmonic Solar Heat Transducers. J. Phys. Chem. C 2016, 120, 2343-2348. [CrossRef]

15. Zhou, L.; Tan, Y.L.; Ji, D.X.; Zhu, B.; Zhang, P.; Xu, J.; Gan, Q.Q.; Yu, Z.F.; Zhu, J. Self-assembly of highly efficient, broadband plasmonic absorbers for solar steam generation. Sci. Adv. 2016, 2, e1501227. [CrossRef]

16. Yeshchenko, O.A.; Kutsevol, N.V.; Naumenko, A.P. Light-Induced Heating of Gold Nanoparticles in Colloidal Solution: Dependence on Detuning from Surface Plasmon Resonance. Plasmonics 2016, 11, 345-350. [CrossRef]

17. Tullius, T.K.; Bayazitoglu, Y. Temperature of a metallic nanoparticle embedded in a phase change media exposed to radiation. Int. J. Heat Mass Transf. 2016, 93, 980-990. [CrossRef]

18. Otanicar, T.P.; Phelan, P.E.; Prasher, R.S.; Rosengarten, G.; Taylor, R.A. Nanofluid-based direct absorption solar collector. J. Renew. Sustain. Energy 2010, 2, 033102. [CrossRef]

19. Zhang, H.; Chen, H.J.; Du, X.Z.; Wen, D.S. Photothermal conversion characteristics of gold nanoparticle dispersions. Solar Energy 2014, 100, 141-147. [CrossRef]

20. Luo, Z.; Wang, C.; Wei, W.; Xiao, G.; Ni, M. Performance improvement of a nanofluid solar collector based on direct absorption collection (DAC) concepts. Int. J. Heat Mass Transf. 2014, 75, 262-271. [CrossRef]

21. Jin, X.; Lin, G.P.; Zeiny, A.; Jin, H.C.; Bai, L.Z.; Wen, D.S. Solar photothermal conversion characteristics of hybrid nanofluids: An experimental and numerical study. Renew. Energy 2019, 141, 937-949. [CrossRef]

22. Neumann, O.; Urban, A.S.; Day, J.; Lal, S.; Nordlander, P.; Halas, N.J. Solar vapor generation enabled by nanoparticles. ACS Nano 2013, 7, 42-49. [CrossRef] [PubMed]

23. Ni, G.; Miljkovic, N.; Ghasemi, H.; Huang, X.; Boriskina, S.V.; Lin, C.-T.; Wang, J.; Xu, Y.; Rahman, M.M.; Zhang, T.; et al. Volumetric solar heating of nanofluids for direct vapor generation. Nano Energy 2015, 17, 290-301. [CrossRef]

24. Gan, Y.A.; Qiao, L. Optical Properties and Radiation-Enhanced Evaporation of Nanofluid Fuels Containing Carbon-Based Nanostructures. Energ. Fuel 2012, 26, 4224-4230. [CrossRef]

25. Hogan, N.J.; Urban, A.S.; Ayala-Orozco, C.; Pimpinelli, A.; Nordlander, P.; Halas, N.J. Nanoparticles Heat through Light Localization. Nano Lett. 2014, 14, 4640-4645. [CrossRef] [PubMed]

26. Neumann, O.; Feronti, C.; Neumann, A.D.; Dong, A.J.; Schell, K.; Lu, B.; Kim, E.; Quinn, M.; Thompson, S.; Grady, N.; et al. Compact solar autoclave based on steam generation using broadband light-harvesting nanoparticles. Proc. Natl. Acad. Sci. USA 2013, 110, 11677-11681. [CrossRef]

27. Saidur, R.; Meng, T.C.; Said, Z.; Hasanuzzaman, M.; Kamyar, A. Evaluation of the effect of nanofluid-based absorbers on direct solar collector. Int. J. Heat Mass Transf. 2012, 55, 5899-5907. [CrossRef]

28. Fang, Z.; Zhen, Y.R.; Neumann, O.; Polman, A.; de Abajo, F.J.G.; Nordlander, P.; Halas, N.J. Evolution of light-induced vapor generation at a liquid-immersed metallic nanoparticle. Nano Lett. 2013, 13, 1736-1742. [CrossRef] [PubMed]

29. Govorov, A.O.; Zhang, W.; Skeini, T.; Richardson, H.; Lee, J.; Kotov, N.A. Gold nanoparticle ensembles as heaters and actuators: Melting and collective plasmon resonances. Nanoscale Res. Lett. 2006, 1, 84-90. [CrossRef] 
30. Otanicar, T.P.; Phelan, P.E.; Golden, J.S. Optical properties of liquids for direct absorption solar thermal energy systems. Solar Energy 2009, 83, 969-977. [CrossRef]

31. Bandarra, E.P.; Mendoza, O.S.H.; Beicker, C.L.L.; Menezes, A.; Wen, D.S. Experimental investigation of a silver nanoparticle-based direct absorption solar thermal system. Energy Convers. Manag. 2014, 84, 261-267. [CrossRef]

32. Rahman, M.M.; Al-Mazroui, W.A.; Al-Hatmi, F.S.; Al-Lawatia, M.A.; Eltayeb, I.A. The role of a convective surface in models of the radiative heat transfer in nanofluids. Nucl. Eng. Des. 2014, 275, 382-392. [CrossRef]

33. Hussain, I.; Graham, S.; Wang, Z.X.; Tan, B.; Sherrington, D.C.; Rannard, S.P.; Cooper, A.I.; Brust, M. Size-controlled synthesis of near-monodisperse gold nanoparticles in the 1-4 nm range using polymeric stabilizers. J. Am. Chem. Soc. 2005, 127, 16398-16399. [CrossRef]

34. Baffou, G.; Quidant, R.; de Abajo, F.J.G. Nanoscale Control of Optical Heating in Complex Plasmonic Systems. ACS Nano 2010, 4 , 709-716. [CrossRef] [PubMed]

35. Lukianova-Hleb, E.; Hu, Y.; Latterini, L.; Tarpani, L.; Lee, S.; Drezek, R.A.; Hafner, J.H.; Lapotko, D.O. Plasmonic Nanobubbles as Transient Vapor Nanobubbles Generated around Plasmonic Nanoparticles. ACS Nano 2010, 4, 2109-2123. [CrossRef]

36. Ni, G.; Li, G.; Boriskina, S.V.; Li, H.X.; Yang, W.L.; Zhang, T.J.; Chen, G. Steam generation under one sun enabled by a floating structure with thermal concentration. Nat. Energy 2016, 1, 16126. [CrossRef]

37. Li, X.Q.; Xu, W.C.; Tang, M.Y.; Zhou, L.; Zhu, B.; Zhu, S.N.; Zhu, J. Graphene oxide-based efficient and scalable solar desalination under one sun with a confined 2D water path. Proc. Natl. Acad. Sci. USA 2016, 113, 13953-13958. [CrossRef]

38. Ma, H.Y.; Bendix, P.M.; Oddershede, L.B. Large-Scale Orientation Dependent Heating from a Single Irradiated Gold Nanorod. Nano Lett. 2012, 12, 3954-3960. [CrossRef]

39. Ye, E.Y.; Win, K.Y.; Tan, H.R.; Lin, M.; Teng, C.P.; Mlayah, A.; Han, M.Y. Plasmonic Gold Nanocrosses with Multidirectional Excitation and Strong Photothermal Effect. J. Am. Chem. Soc. 2011, 133, 8506-8509. [CrossRef] [PubMed]

40. Baffou, G.; Bon, P.; Savatier, J.; Polleux, J.; Zhu, M.; Merlin, M.; Rigneault, H.; Monneret, S. Thermal Imaging of Nanostructures by Quantitative Optical Phase Analysis. ACS Nano 2012, 6, 2452-2458. [CrossRef]

41. Govorov, A.O.; Richardson, H.H. Generating heat with metal nanoparticles. Nano Today 2007, 2, 30-38. [CrossRef]

42. Lukianova-Hleb, E.Y.; Volkov, A.N.; Lapotko, D.O. Laser pulse duration is critical for the generation of plasmonic nanobubbles. Langmuir 2014, 30, 7425-7434. [CrossRef]

43. Hou, L.; Yorulmaz, M.; Verhart, N.R.; Orrit, M. Explosive formation and dynamics of vapor nanobubbles around a continuously heated gold nanosphere. New J. Phys. 2015, 17, 13050. [CrossRef]

44. Vera, J.; Bayazitoglu, Y. Temperature and heat flux dependence of thermal resistance of water/metal nanoparticle interfaces at sub-boiling temperatures. Int. J. Heat Mass Transf. 2015, 86, 433-442. [CrossRef]

45. Wen, D. Intracellular hyperthermia: Nanobubbles and their biomedical applications. Int. J. Hyperth. 2009, $25,533-541$. [CrossRef] [PubMed]

46. Chen, X.L.; Munjiza, A.; Zhang, K.; Wen, D.S. Molecular Dynamics Simulation of Heat Transfer from a Gold Nanoparticle to a Water Pool. J. Phys. Chem. C 2014, 118, 1285-1293. [CrossRef]

47. Huang, J.; He, Y.; Hu, Y.; Wang, X. Steam generation enabled by a high efficiency solar absorber with thermal concentration. Energy 2018, 165, 1282-1291. [CrossRef]

48. Modest, M.F. CHAPTER 20-The Monte Carlo Method for Thermal Radiation, 2nd ed.; Modest, M.F., Ed.; Academic Press: Burlington, MA, USA, 2003; pp. 644-679.

49. McPeak, K.M.; Jayanti, S.V.; Kress, S.J.P.; Meyer, S.; Iotti, S.; Rossinelli, A.; Norris, D.J. Plasmonic Films Can Easily Be Better: Rules and Recipes. ACS Photonics 2015, 2, 326-333. [CrossRef]

50. Zeiny, A.; Jin, H.; Lin, G.; Song, P.; Wen, D. Solar evaporation via nanofluids: A comparative study. Renew. Energy 2018, 122, 443-454. [CrossRef] 